\title{
Nurses' Perspectives on Compassionate Care for Patients with Exacerbated Chronic Obstructive Pulmonary Disease
}

Marit Kvangarsnes ${ }^{1,2 *}$, Henny Torheim ${ }^{1,2}$, Torstein Hole ${ }^{3,4}$ and Paul Crawford ${ }^{5,6}$

${ }^{1}$ Aalesund University College, Aalesund, Norway

${ }^{2} \mathrm{Helse}$ Møre og Romsdal, Norway

${ }^{3}$ Medical Clinic, Helse Møre og Romsdal, Norway

${ }^{4}$ Medical Faculty, Norwegian University of Science and Technology (NTNU), Norway

${ }^{5}$ Professor of Health Humanities at the School of Health Sciences at The University of Nottingham, UK

${ }^{6}$ Professorial Fellow at the Institute of Mental Health, UK

\begin{abstract}
The aim of the study was to gain insight into intensive care nurses' perspectives on compassionate care for patients with exacerbated chronic obstructive pulmonary disease. Patients who experience acute exacerbation are vulnerable because they experience a life-threatening situation and are wholly dependent on health-care interventions to relieve breathlessness. A hermeneutic phenomenological approach was used. Three focus group interviews with intensive-care nurses were conducted at two hospitals in western Norway in the autumn of 2009. One group had five participants, and two groups had six participants each $(N=17)$. A collaborative practice was regarded as essential to provide compassionate care in these situations. Three main themes emerged from the data: (a) preparing to care for breathlessness; (b) establishing a trusting relationship; (c) to approach each patient as a person with unique needs. These were experienced as important in rendering compassionate care for patients with exacerbation of chronic obstructive pulmonary disease. The study showed that compassionate care involves interventions at different levels with particular attention to simple comforting care and technical adjustments. The study also showed a need for enhanced multidisciplinary cooperation in planning the subsequent clinical pathway.
\end{abstract}

Keywords: COPD; Qualitative research; Compassionate care; Critical care; Nursing, acute care; Focus groups interviews; Collaborative practice

\section{Introduction}

About 65 million people have chronic obstructive pulmonary disease (COPD) and COPD is estimated to be the third cause of death worldwide by 2030 [1]. Sometimes patients with COPD experience an exacerbation. These patients are vulnerable because they experience a life-threatening situation and are wholly dependent on health-care interventions to relieve breathlessness [2-5]. Exacerbation of COPD is treated worldwide with non-invasive ventilation (NIV) $[6,7]$.

Gaps in patients' desires for care at the end-of-life and what they actually receive are well documented (8). It has been previously reported that half of patients with COPD would elect not to be put on a ventilator if there were little hope of recovery $[8,9]$.

Sørensen et al. [10] found that the following interrelated components facilitated successful NIV: patient adaptation to the treatment, effective ventilation and nurses' attentiveness to patients' perceptions of NIV. According to experienced nurses, it is important to be attentive and understanding when interacting with patients; to engage in calm communication with patients; to evaluate data on an ongoing basis; to provide encouragement, social support and immediate solutions to patients; to meet clinically the physical needs of patients; and to alleviate the discomfort of patients. One study found that ICU treatment is often characterised by a low degree of patient power and patient participation [11].

Lomborg et al. [12] explored assisted body care in hospitalised patients with severe COPD. They found that patients struggled for self-preservation in both symbolic and practical ways. A threefold strategy of coping with dependency, minimising the risk of escalating breathlessness and refusing to give up was used to manage assisted body care. Lomborg et al. [12] also found that patients' key problems with assisted body care related not only to physical symptoms but also to a feeling of dependency.

The establishment of good communication practices is fundamental in the provision of care to patients with COPD [13-15]. Gysels and Higgenson stated that diagnosis and prognosis need to be rethought in a model to suit the condition of COPD. They emphasised taking a stepwise approach throughout the illness trajectory within a framework focused on surveillance. Other recommendations include taking a holistic and patient-centred approach to prognosis, recognising uncertainty and focusing on quality of life. Integrating diagnosis with prognosis as early as possible in communication with patients is also of importance [15].

\section{Compassionate Care}

The need for compassionate care in modern health care has been discussed worldwide [16-23]. Compassion fatigue and burnout are frequently associated with intensive care nursing practice. Support for engagement in health promotional behaviours may be of help to nurses' well-being in counteracting compassion fatigue and enhancing compassion [24]. The term compassion is defined in different ways. In this paper, we define compassion as a strong awareness of or sensitivity

*Corresponding author: Marit Kvangarsnes, Associate Professor, Faculty of Health Sciences Aalesund University College, Aalesund, Norway, Tel: +47 99400695; E-mail: mk@hials.no

Received October 10, 2013; Accepted December 11, 2013; Published Decembe 16, 2013

Citation: Kvangarsnes M, Torheim H, Hole T, Crawford P (2013) Nurses' Perspectives on Compassionate Care for Patients with Exacerbated Chronic Obstructive Pulmonary Disease. J Allergy Ther 4: 158. doi:10.4172/21556121.1000158

Copyright: ( 2013 Kvangarsnes M, et al. This is an open-access article distributed under the terms of the Creative Commons Attribution License, which permits unrestricted use, distribution, and reproduction in any medium, provided the original author and source are credited. 
to the pain or suffering of others that results in taking verbal, non-verbal or physical action to remove, reduce or alleviate the impact of such affliction. This definition includes openness of attention, awareness of suffering, motivation and action [25]. Many studies have identified a lack of compassion in modern health care and nursing [26-28].

According to Straughair $[29,30]$ compassion in nursing is rooted in the Christian ideals that were instilled by Florence Nightingale into the characterisation of the professional nurse. As the profession has evolved, the value of compassion seems to have diminished.

In her 2011 work, Bradshaw called for compassionate and skilled nurses to meet the needs of patients [19]. She presented three key principles for nursing based on historical analysis, which can be related to the modern nursing situation: (a) the character of the nurse, (b) competence in knowledge and skills and (c) ward leadership. These principles have given a framework for interpreting the data in this article.

Compassion is an important value in nursing. It involves sensitivity to the suffering or distress of others, along with a commitment to try to relieve this suffering [25]. It is therefore a very relevant concept in the provision of care to patients with COPD exacerbation because of the intensity of distress and discomfort that can be experienced. Benner et al. [31] stated that 'learning nursing's focal practices, such as being present for patients and bearing witness to their suffering, patient advocacy, and responsibility, are central to formation of the nurse, and they are also formative of practice and learning communities in nursing' (p. 192). A review of the literature revealed that little is known about nurses' perspectives on compassionate care in exacerbation of COPD. The present study investigates intensive care nurses' perspectives on compassionate care for patients with exacerbation of chronic obstructive pulmonary disease in different phases of the illness trajectory in the ICU. Our understanding of excellence in critical care nursing is based on six attributes: values, vision, mastery, passion, action, and balance [32]. The research question is what do nurses perceive as compassionate care in the treatment of COPD exacerbation in the ICU?

\section{Materials and Methods}

\section{Design}

The study has a hermeneutic phenomenological approach [33-35]. Focus group interviews with experienced nurses were conducted to gather data in an attempt to answer the research question $[34,35]$.

\section{Participants}

The participants were found through purposeful sampling [35]. Nurses were asked to participate based on their knowledge and experience in treating patients with acute exacerbation of COPD. Criteria for inclusion were education as an intensive-care nurse and a minimum of two years' work experience caring for patients with COPD exacerbation. The participants were recruited face-to-face during work hours by one of the researchers. Two nurses declined to participate because of other obligations. A total of 17 intensive-care nurses participated in the study. They were divided into groups of 5 or 6 participants. The participants were Norwegian women between 41 and 62 years, and all had more than 10 years' nursing experience.

\section{Data collection}

Three focus group interviews were conducted at two hospitals in western Norway in the autumn of 2009. Focus groups were used because this method often gives rich information when the participants have shared experiences [36,37]. The interviews were conducted in rooms where the groups would be undisturbed. Efforts were made to create a relaxed atmosphere for the interviews. Two authors of this study (intensive-care nurses who were also trained in conducting focus group interviews) fulfilled the roles of secretary and moderator during the interviews.

The moderator used an interview guide, which had been developed based on the research question, the theoretical framework of the project and earlier research. The participants were asked what they considered as compassionate care in the different phases of the treatment of COPD exacerbation in the ICU. The interview process did not have a rigid structure. A secretary took notes about what was discussed and the group interaction during the interviews, the duration of which was typically about 90 minutes. At the end of the interviews, the secretary summarised the discussion, and the participants confirmed that the summary was in agreement with what they wished to express.

\section{Analysis}

The interviews were audiotaped and transcribed verbatim by the same researchers who had conducted them [38]. The transcribed interviews were read by all the researchers, with the exception of one researcher. The important parts of the text were translated into English by one author whose native language is English. The data were coded by the first author. The focus of the analysis of the transcribed interviews was on what compassionate care meant to the nurses in the different phases of care and treatment during acute COPD exacerbation. The interpretive process can be described in terms of the hermeneutic circle; that is, the transcribed interviews were interpreted in terms of their parts, and the parts were interpreted in terms of the whole [34]. The meaning of the text, based on the research question, was continually questioned. The data were first coded with respect to three phases: preparation, mask treatment and recovery. Subthemes were developed, thus giving supplementary understanding of the three main themes. A draft of the themes, along with examples from the transcribed interviews, was subjected to critical consideration and analysis by all the authors.

In the hermeneutic research tradition, researchers must be conscious of their own preunderstanding and how it might affect the reading of the data. It is also important to observe and note the group interactions in the interviews because what the participants say can be confirmed, reinforced or contradicted within the group discussion [39]. Transcriptions of the interviews are included to show the interactions between the participants and how they communicated about different subjects [34]. Linguistic analysis of the participants' interview responses was used to interpret the text.

Enhancing trustworthiness in different steps in the research process is explicitly and precisely communicated. The researchers' positions and pre-understanding are reflected in the text [33]. The conceptual focus of compassionate care served as a lens to give the project a focus on good care and is explicitly described. Hermeneutic circle practices brought forth patterns of interpretation, which are carefully described in this text. Both the interview transcription and the field notes about the group interaction were important resources in the analysis. The researchers strived for dialogical intersubjectivity [34]. The cooperation of the researchers is described. It is probable that these findings can be transferred to other contexts involving the treatment of COPD exacerbation. Data were gathered until themes became repetitive and redundant. After three interviews had been conducted, the researchers 
determined that no new information could be gleaned by further data collections [34]'.

\section{Ethics}

The study was a part of a larger research project approved by the Regional Committee for Medical and Health Research Ethics (4.2008.2869). The participants received both oral and written information about the study. They provided informed consent before participating in the study.

\section{Findings}

Seventeen intensive-care nurses described what they had experienced to be important in rendering compassionate care during COPD exacerbation. A collaborative practice was regarded as essential to provide compassionate care in these situations. The analysis revealed three themes in the nurses' descriptions: (1) preparing to care for breathlessness, (2) establishing a trusting relationship, (3) treating each patient as a person with unique needs. These three main themes and their related subthemes constitute central elements in nurses perspectives on compassionate care in the various phases of treating COPD exacerbation.

\section{Preparing to care for breathlessness}

When the moderator asked the nurses how they prepared to meet patients with COPD exacerbation, all groups of nurses provided descriptive responses. In addition to emphasising the importance of nursing competence in mask- treatment, they highlighted the value of a careful preparation for basic care and the importance of cooperation.

Caring environment: The nurses interviewed for this study stated that they prepared for their meeting with patients with COPD exacerbation by carrying out the following tasks: ensuring that the patient's room has fresh air and is at a suitable temperature, gathering the proper equipment and medication for the treatment in advance, installing bedrails and having enough pillows available. The nurses said they were conscious of the importance of providing patients with a properly prepared room so that it would be easy for them to attend to these patients. In addition, they emphasised that upon arrival at the unit, patients should encounter a minimum number of individuals.

Ensuring cooperation: All groups emphasised cooperation with the other nurses and the physicians. The following interview excerpt concerns situations in which close cooperation between nurses is necessary for providing good care to patients (interview 3 ).

Nurse (N) 17: Something else that is very important is that we usually receive very good help from each other. We understand what the others need for help. That is reassuring. We are seldom on our own when we are about to receive a patient who is critically ill.

N 12: It is also very important that there are two of us when we, for instance, are about to put on the mask. It is more comfortable for the patient that way.

To express the importance of cooperation between the nurses and what effect this may have on patients, the nurses used the following positively loaded words and phrases to describe the cooperation: 'good help', 'reassuring,' 'mental support', 'comfortable for the patient'.

The nurses also highlighted the importance of clarifying aspects of the treatment with the physician responsible for the patient before the nurses started administering the treatment e.g., whether or not patients should undergo respirator treatment if their condition does not change within a reasonable time period.

\section{Competence in mask treatment}

The nurses who participated in the focus group interviews were experienced intensive-care nurses. They possessed confidence in their ability to administer mask treatment, as exemplified in the following statement by one nurse ( $\mathrm{N} \mathrm{15}$; interview 3 ): 'I think we are very good at treating COPD patients. The nurses also called attention to the importance of receiving clear treatment instructions from physicians so as to allow them to function more independently. The nurses considered knowledge, technical skills and experience to be paramount for their successful administration of mask treatment. One nurse spoke of her own development from novice to expert with respect to care and treatment of patients with COPD exacerbation. Initially, she had been very insecure and nervous when these patients arrived in her unit. With experience, she gained confidence in her ability and felt equipped to deal with these kinds of situations.

\section{Establishing a trusting relationship}

The nurses spoke of the importance of creating a sense of safety, administering effective mask treatments, alleviating pain and allowing patients to get enough sleep and rest so as to improve their patients health.

Creating a sense of safety: The nurses emphasised the importance of achieving successful mask treatment. They told that the patients responded in different ways to the mask treatment. Patients who had had previous experience receiving this treatment coped fairly well. One nurse ( $\mathrm{N}-7$; interview 2), who used a metaphor to explain the mask treatment to her patients, stated, 'I have a sentence I use. I bend down to the patient and say into the ear, "See this mask; it is your best friend". In the following interview excerpt (interview 1), four nurses describe what they think is important for them to do when meeting with a patient for the first time:

\section{Moderator (M): Meeting the patient, what is prioritised?}

N 6: What is important? To create a sense of safety.

N 1: To be calm.

N 2: Not pressing the mask on right away. Give them some time.

N 5: Basic information, without too much talking, only enough to make them understand what is going on.

In this interview excerpt, the nurses communicated in a reserved, calm and precise manner, similar to how they would communicate with patients with COPD exacerbation. The nurses also said it was important to convey to patients that they were trying to help. In situations like this one, nurses must devote their complete attention to problems associated with breathlessness.

Compassionate treatment: During the interviews, the nurses engaged in intense discussions about ways in which to help patients cope with the mask. These ways included finding the proper mask, obtaining information about the arterial blood gas values, finding and using the right pressure for each patient, establishing eye contact when giving information to patients, giving sedation and offering pauses in the treatment, ensuring that patients have a comfortable sitting position in bed, providing patients with an ample number of pillows, staying with patients at all times and working together with another nurse when administering the mask to a patient. In addition, the nurses said it was important to respond positively whenever a patient cooperated during mask treatment. Patients who had never gone through mask treatment sometimes found it to be particularly difficult. One of the 
nurses (N 3) explained the situation as follows (interview 1): 'If I have a patient who has never experienced the mask, I always hold up the mask in front of his or her face so that they can feel the air current. I never attach it right away. I hold it close to them so that they can feel how it is. All groups described how they cooperated with patients to help them accept the mask treatment. Time shortage was often identified as a main impediment with respect to giving patients the kind of continuous observation often required.

Alleviating pain: According to the nurses, the exacerbation phase was characterised by patients' breathing problems and pain. In the following interview excerpt, three nurses discuss patients' facial pain, which is possibly caused by the mask treatment (interview 3):

N 14: What I find most challenging is that they shall endure the mask and manage to cooperate with it. All this about alleviating pain ... it's enormously challenging.... They get blisters on their noses ... that pressure on the nose.

\section{N 15: Yes, almost down to the nose bone.}

N 14: To soften the pain, put on duoderm and administer small doses of morphine, all to make them stand this. All of this is just great, and it has a huge impact on the pain, the feeling of unpleasantness. It's just calming.

In this excerpt, the nurses conveyed their involvement in alleviating patients' pain caused by mask treatment. Among the initiatives mentioned were the use of painkillers, wound care and the switching of masks to find an appropriate one. All groups also discussed how to draw blood for blood tests in the least painful way. The nurses were all engaged in this topic, and many of them joined the conversation.

Balancing mask treatment with sleep and rest: Ensuring that patients received enough sleep and rest during their treatment in an ICU was viewed as a challenge by the nurses. In the following interview excerpt, three nurses discuss how maintaining a balance between mask treatment, sedation, sleep and rest for their patients can be especially difficult (interview 2):

N 10: We see that if there is night after night without sleep, then they may turn psychotic, hallucinate, and probably end up on the respirator.

N 9: Because, yes ...

$\mathbf{N} 7$ : This is a thorny road. If you manage to get some natural sleep - if it's only for an hour or two - it's worth its weight in gold.

N 10: But I think that if we manage to calm them down a bit, and it works all right with the BIPAP [bi-level positive airway pressure], then they manage to relax, and actually fall asleep because they are so exhausted. And if they, in addition, get a small dash of morphine..

The nurses discussed this topic with great empathy for their patients. They used metaphors and positively laden words and expressions like 'thorny road' and 'worth its weight in gold' to describe these situations. The discussion also included their views on what was the best sleeping position and how best to attune to patient needs in this area, for example, in one instance, finding a chair to work better than a bed.

\section{Treating the patient as a person}

The nurses revealed that many of their patients had benefitted greatly from mask treatment and that attending to individual needs was easier in the recovery phase.

Meeting the patients' fear: There was a consensus in the groups that medical treatment should be on the patient's terms. The nurses provided many examples of how they had tried to bring about as predictable a situation as possible. To give patients a sense of being in control, they mentioned the importance of giving information to patients and of working together with the patients to make agreements and plans for the clinical pathway.

All groups talked about patients' fear of death. The nurses commented that it was important for them to respond adequately when patients expressed this fear. In addition, the nurses highlighted the importance of cooperating with the physician, the family, and possibly the clergy when planning a patient's progress. The nurses referred to situations in which patients expressed relief when such plans had been made.

The nurses also identified taking care of the next of kin as an important aspect of their work. One group pointed out the importance of including the next of kin early in the process of giving information about the treatment and speaking openly to patient and family about the illness. There was also common agreement that many next of kin tended to be exhausted. In the following interview excerpt, two nurses discuss the problems encountered by nurses with regard to patients' next of kin (interview 1):

N 2: Next of kin can often be of help, but sometimes they are too exhausted to do so.

N 3: In these cases, I wish we could tell them that they will get help when they get home. But we can't do that. Whether they can get help or not is dependent on the municipality they live in.

Here, the nurses noted a lack of resources in some of the local health services. The nurses saw it as important to be realistic and honest about the patient's condition. Information and involvement in care giving activities was seen as a crucial component in providing compassionate care for the patient and the family.

Protecting patients' autonomy: In the focus group interviews, the nurses provided several examples of how they tried to safeguard patient integrity. The following short excerpt is one such example (interview 3 ):

N 13: We had a patient who wanted a glass of red wine in the evening, and that was probably not compatible with [the taking of a] sleeping pill or morphine. But she got it......

N 16: It's important not to take away from them their last bit of integrity.

The nurses here show that they want to grant a patient's wish even if it might be contrary to medical treatment. In another group, the nurses discussed patients' need for a smoke. Some patients wanted to leave the ICU as soon as possible because they were not allowed to smoke there. Other patients had an adhesive nicotine patch smoking bandage. The interviewed nurses expressed different attitudes to the smoking problem. One nurse stated the following opinion (interview 1):

N 3: We meet patients who see smoking as their one and only consolation. It is COPD in a late stage. I remember one who said that the only thing that had him get up in the morning, and that made it worthwhile even to consider to get up, was that he could go out to the veranda and enjoy half a cigarette. In circumstances like this, I cannot criticize someone for smoking. He should be allowed to have this pleasure in the short time he has left.

This nurse was accepting of the patient's choice. Instead of moralizing, she was determined to let him keep what he viewed as his only consolation left in life. The nurses experienced a sense of shame 
among patients who smoked and that it was important not to adopt a condescending attitude to patients on this issue.

Sensitive-assisted personal body care: The nurses remarked that many patients are unkempt when they are admitted to hospital simply because they do not have sufficient strength to maintain their personal hygiene. They said that they would not proceed with a body wash if doing so might worsen the patient's situation. The nurses viewed body care as an area in which patients should have a heavy influence with respect to when and how this care should be administered. They also admitted that it was sometimes tempting just to go ahead with providing personal body care without first consulting with the patient.

\section{Discussion}

In the present study, focus group interviews were conducted with nurses to determine what they considered to be important in providing compassionate care to patients with exacerbation of COPD. The nurses emphasised the importance of carrying out practical preparations and cooperating with colleagues and ensuring cross-disciplinary communication. In addition, the nurses explained the importance of creating a sense of safety with patients as a means by which to achieve successful mask treatment. They also considered nurses' possession of theoretical and practical competence to be essential in providing quality care. To advance recovery of the patients, the nurses stated that they help them rest and manage their pain. Their treatment of each patient as a person was considered another important element of compassionate nursing care. The nurses expressed a desire to maintain patients' autonomy even though doing so may sometimes conflict with medical treatment.

The term compassionate care is broadly defined. It relates to core values in nursing and is found in several religions [31]. The term is used in the present study as a theoretical framework in which to analyse the data so as to illuminate what compassionate care means during acute exacerbation of COPD. The term is used systematically here to explore the interviewed nurses' views about interventions and conditions necessary for compassionate care during various phases of exacerbation of COPD in the ICU setting.

The nurses stressed the importance of adopting a careful approach during the initial stages of mask treatment, particularly in treating patients with no previous experience with NIV. Studies have shown that patients may find the mask treatment frightening $[4,5]$ and that successful treatment depends on how they adapt to it [10]. Torheim and Gjengedal [4] have shown that time is often limited in these situations. The problems associated with the limited time available to provide proper treatment are discussed in the present study. Lack of time has in earlier research been identified as a barrier to compassionate care [40].

The nurses revealed that patients undergoing mask treatment sometimes experience substantial pain and suffer wounds, which may require a variety of interventions. In these situations, managing pain is an important element in compassionate care. Previous research, however, has not illuminated this problem clearly.

The findings reveal that the nurses encouraged their patients to have a say with respect to the small details of their care before beginning treatment. These small gestures (e.g., allowing patients to familiarize themselves with mask airflow) were considered important because they allowed patients to feel more in control. The findings also provide a deeper understanding of how the nurses make such modest but in this context significant care or technical adjustments in terms of use of pillows and different sitting positions to ensure optimal rest for their patients and to maximize the benefit from the treatment. The nurses also emphasized the importance of communicating with patients about the disease progression and of taking a holistic approach to treating their patients. The acknowledgement of a patient's fear of death in the context of the acute existential challenge of COPD, may represent another form of compassionate care in these situations.

Lomborg et al. [12] reported that patients found it difficult to be dependent on assisted body care. Although the nurses in the present study stated that they listened to patients talking about assisted body care, patients' reflections about their experience with this type of care are lacking from this study.

A previous study found that patients may sometimes be afraid to sleep because they are uncertain about whether they are being sufficiently monitored [5]. In the present study, the nurses described the negative effects of inadequate rest on a patient's health. In this situation, it becomes important for nurses to identify the patient's fear and counter it by creating a safe and comforting environment.

Bradshaw's [19] three main principles of nursing seem to be highly relevant when caring for patients experiencing acute exacerbation of COPD. Nurses must be perceptive of their patients' discomfort so as to meet their needs. In addition, nurses must possess extensive knowledge of the disease and technical skills to provide treatment. Because COPD is a chronic disease, it is important that leaders in municipal health services understand the daily challenges that both patients and families face, and ensure that adequate resources are provided.

According to Bradshaw the development of the character gave the nursing profession its ethos. The good of the patient and not any personal pleasure or profit-seeking was the sole motive [19]. In this study the nurses demonstrated ethically and respectful reflections on the patients' right to make independent decisions about their body and actions free from interference or coercion of others.

The data represent intensive-care nurses' perspectives on the meaning of delivering compassionate care to patients with exacerbation of COPD. If the patients had been interviewed on this topic, they might have valued different aspects of the treatment. It is also possible that the interpretation of the data may have been affected by the first author's pre-understanding as an intensive-care nurse [33].

\section{Conclusions}

This study demonstrates the relevance of the concept of compassionate nursing care with respect to patients with acute exacerbation of COPD. In this situation, nurses must deliver compassionate care by being sensitive to patients' pain and breathlessness and deeply committed to relieving these symptoms. Nurses should also strive to achieve successful and comfortable mask treatment and work together with the patient, as well as other individuals involved, to plan the subsequent clinical pathway. Compassionate care in these situations means a holistic patient-centred approach, which may not always be in accordance with the recommended treatment and which is sensitive to the comfort generated in small care gestures and technical adjustments in the distressing context of COPD.

A professional community must be developed to promote cooperation among the different professions involved in treating patients with exacerbation of COPD. Clear treatment guidelines are also needed to help nurses function more independently. In addition, nurses need to possess both practical and theoretical skills to treat patients successfully. One such skill involves helping patients adapt to the mask treatment. Because compassionate care involves interventions 
Citation: Kvangarsnes M, Torheim H, Hole T, Crawford P (2013) Nurses' Perspectives on Compassionate Care for Patients with Exacerbated Chronic Obstructive Pulmonary Disease. J Allergy Ther 4: 158. doi:10.4172/2155-6121.1000158

at different levels, health-care leaders must be aware of the need for competent personnel in these situations. A need also exists for leaders in municipal health services who possess the ability to prioritize resources to patients and next of kin in the different phases of the disease.

\section{Ethical Approval}

The study was a part of a larger research project approved by the Regional Committee for Medical and Health Research Ethics (4.2008.2869).

\section{Funding Statement}

We would like to thank Helse Midt-Norge, Helse Møre og Romsdal, and Aalesund University College for their support.

\section{References}

1. World Health Organization (2013) Chronic obstructive pulmonary disease (COPD).

2. Bailey PH (2001) Death stories: acute exacerbations of chronic obstructive pulmonary disease. Qual Health Res 11: 322-338.

3. Barnett $M$ (2005) Chronic obstructive pulmonary disease: a phenomenological study of patients' experiences. J Clin Nurs 14: 805-812.

4. Torheim H, Gjengedal E (2010) How to cope with the mask? Experiences of mask treatment in patients with acute chronic obstructive pulmonary diseaseexacerbations. Scand J Caring Sci 24: 499-506.

5. Kvangarsnes M, Torheim H, Hole T, Öhlund LS (2013) Narratives of breathlessness in chronic obstructive pulmonary disease. J Clin Nurs 22: 30623070.

6. Brochard L, Mancebo J, Elliott MW (2002) Noninvasive ventilation for acute respiratory failure. Eur Respir J 19: 712-721.

7. Ambrosino N, Vagheggini G (2007) Non-invasive ventilation in exacerbations of COPD. Int J Chron Obstruct Pulmon Dis 2: 471-476.

8. Au DH, Udris EM, Fihn SD, McDonell MB, Curtis JR (2006) Differences in health care utilization at the end of life among patients with chronic obstructive pulmonary disease and patients with lung cancer. Arch Intern Med 166: 326331.

9. Rocker GM, Dodek PM, Heyland DK; Canadian Researchers at the End of Life Network (2008) Toward optimal end-of-life care for patients with advanced chronic obstructive pulmonary disease: insights from a multicentre study. Can Respir J 15: 249-254.

10. Sørensen D, Frederiksen K, Grøfte T, Lomborg K (2013) Nurse-patien collaboration: a grounded theory study of patients with chronic obstructive pulmonary disease on non-invasive ventilation. Int J Nurs Stud 50: 26-33.

11. Kvangarsnes M, Torheim H, Hole T, Öhlund LS (2013) Intensive care unit nurses' perceptions of patient participation in the acute phase of chronic obstructive pulmonary disease exacerbation: an interview study. J Adv Nurs 69: 425-434

12. Lomborg K, Bjørn A, Dahl R, Kirkevold M (2005) Body care experienced by people hospitalized with severe respiratory disease. J Adv Nurs 50: 262-271.

13. Andenaes R, Kalfoss MH, Wahl AK (2006) Coping and psychological distress in hospitalized patients with chronic obstructive pulmonary disease. Heart Lung 35: 46-57.

14. Gardiner C, Gott M, Payne S, Small N, Barnes S, et al. (2010) Exploring the care needs of patients with advanced COPD: an overview of the literature. Respir Med 104: 159-165.

15. Gysels M, Higginson IJ (2010) The experience of breathlessness: the social course of chronic obstructive pulmonary disease. J Pain Symptom Manage 39: $555-563$

16. Richardson A (2004) Creating a culture of compassion: developing supportive care for people with cancer. Eur J Oncol Nurs 8: 293-305.

17. Martinsen K (2006) Care and Vulnerability. Akribe: Oslo.

18. Giesbrecht M, Crooks VA, Williams A (2010) Perspectives from the frontlines: palliative care providers' expectations of Canada's compassionate care benefit programme. Health Soc Care Community 18: 643-652.
19. Bradshaw A (2011) Editorial: the future of clinical nursing: meeting the needs of patients for compassionate and skilled nurses? J Clin Nurs 20: 1797-1800.

20. Insel TR (2012) Compassionate allowance for people with schizophrenia? Schizophr Res 140: 15-16.

21. Crawford P, Gilbert P, Gilbert J, Gale C, Harvey K (2013) The language of compassion in acute mental health care. Qual Health Res 23: 719-727.

22. Crawford $P$ (2013) Compassion is not just for nurses, it's for managers too Public Servant.

23. Crawford P (2013) The NHS and the true meaning of compassion. Health \& Social Care Reform. GovToday. Editor's Feature.

24. Neville K, Cole DA (2013) The Relationships Among Health Promotion Behaviors, Compassion Satisfaction in Nurses Practicing in a Community Medical Center. J Nurs Adm 43: 348-354.

25. Gilbert P (2009) The Compassionate Mind. Constable Robinson: London.

26. Friele RD, Sluiis EM, Legemaate J (2008) Complaints handling in hospitals: an empirical study of discrepancies between patients' expectations and their experiences. BMC Health Serv Res 8: 199.

27. Yoder EA (2010) Compassion fatigue in nurses. Appl Nurs Res 23: 191-197.

28. Circenis K, Millere I (2011) Compassion fatigue, burnout and contributory factors among nurses in Latvia. Procedia - Social and Behavioral Sciences 30: 2042-2046

29. Straughair C (2012) Exploring compassion: implications for contemporary nursing. Part 1. Br J Nurs 21: 160-164.

30. Straughair C (2012) Exploring compassion: implications for contemporary nursing. Part 2. Br J Nurs 21: 239-240, 242-244.

31. Benner P, Sutphen M, Leonard V, Day L (2010) Educating Nurses. A Call fo Radical Transformation. Jossey-Bass: San Francisco.

32. Morton GM, Fontaine DK (2013) Critical Care: A Holistic Approach. Wolters Kluwer Lippincott Wiliams \& Wilkins.

33. Gadamer HG (1976) Philosophical Hermeneutics (Linge DE edn \& trans). University of California Press: Berkeley.

34. Kvale S, Brinkmann S (2009) InterViews: Learning the Craft of Qualitative Research Interviewing, 2nd edn. Sage: Los Angeles.

35. Malterud K (2012) Fokusgrupper som forskningsmetode for medisin og helsefag [Focus groups as method in medicine and health research] Universitetsforlaget: Oslo.

36. Webb C, Kevern J (2001) Focus groups as a research method: a critique of some aspects of their use in nursing research. J Adv Nurs 33: 798-805.

37. Freeman T (2006) 'Best practice' in focus group research: making sense of different views. J Adv Nurs 56: 491-497.

38. Morse JM, Richards L (2002) Readme First for a User's Guide to Qualitative Methods. Sage, Thousand Oaks: CA.

39. Kitzinger J (1994) The methodology of Focus Groups: the importance of interaction between research participants. Sociology of Health \& Illness 16: 103-121.

40. Cornwell J, Goodrich J (2009) Exploring how to ensure compassionate care in hospital to improve patient experience. Nurs Times 105: 14-16. 